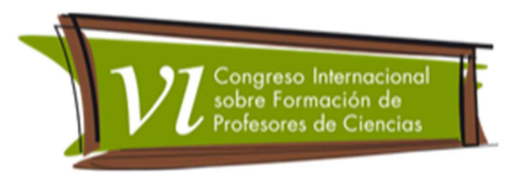

\title{
Partilhando uma experiência de ensino sobre gênero e sexualidade em um curso de formação de professores de Ciências e Biologia
}

Souza, Marcos Lopes de ${ }^{1}$

Categoria 1: Reflexões e experiências de inovação na sala de aula.

\section{Resumo}

Este trabalho discute uma experiência de abordagem das questões de gênero e sexualidade em um curso de formação de professores de Ciências e Biologia vinculado ao Plano Nacional de Formação de Professores da Educação Básica (PARFOR). As ações pedagógicas foram desenvolvidas em três componentes curriculares nomeados de Seminários Temáticos, totalizando 45 horas e a proposta foi pautada em uma perspectiva desestabilizadora e não prescritiva com a utilização de estratégias didáticas diversificadas. Os professores-cursistas (trinta e sete, ao todo) compreenderam a influência dos olhares socioculturais sobre a produção dos gêneros e das sexualidades e reconheceram a existência de processos discriminatórios nos espaços educativos como a homofobia, contudo, se sentem receosos de debatê-los e sofrerem represálias por parte de familiares ou da gestão escolar.

\section{Palavras-chave}

Formação em serviço, gênero, sexualidade e diferenças.

\section{Introdução}

O ensino sobre a sexualidade nos espaços escolares formais foi construído em uma perspectiva normatizadora com a preocupação de controlar os pensamentos, as ações e os desejos das crianças e adolescentes em torno do sexo e pautando-se numa visão higienista, em busca de um sexo dito "saudável". Mesmo com a elaboração do tema Orientação Sexual nos Parâmetros Curriculares Nacionais (PCN), a ênfase continuou nos aspectos prescritivos e de regulação dos corpos, dos gêneros e das sexualidades ao focalizar a redução da

\footnotetext{
${ }^{1}$ Programa de Pós-Graduação em Educação Científica e Formação de Professores (PPGECFP) do Departamento de Ciências Biológicas (DCB) da Universidade Estadual do Sudoeste da Bahia (UESB), campus de Jequié. Email: marcoslsouza@ig.com.br.
} 
Revista Tecné, Episteme y Didaxis: TED. Año 2014, Número Extraordinario. ISSN Impreso: 0121-3814, ISSN web: 2323-0126 Memorias, Sexto Congreso Internacional sobre Formación de Profesores de Ciencias. 08 al 10 de octubre de 2014, Bogotá

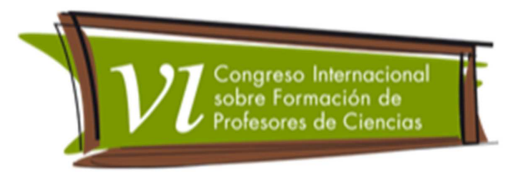

gravidez na adolescência e a prevenção às doenças sexualmente transmissíveis, enquanto as questões ligadas ao sexo como fonte de prazer e à discriminação por gênero e orientação sexual continuaram à margem do currículo (César, 2009; Figueiró, 2010).

Em se tratando dos cursos de Licenciatura em Ciências Biológicas, 'pesquisas como a de Silva \& Megid Neto (2006) e de Souza \& Dinis (2010) ressaltaram que a formação inicial em relação à sexualidade ainda é precária e que a abordagem tem se centralizado nas discussões sobre a fisiologia do corpo humano, os aspectos da reprodução humana e a saúde reprodutiva e que as discussões sobre gênero e diversidade sexual estão condicionadas às opções dos docentes universitários. Os estudos também têm mostrado que os educadores desta área conhecem pouco sobre as orientações curriculares oficiais sobre a abordagem da sexualidade na escola.

Contudo, mesmo quando as questões de gênero e sexualidade estão presentes em sua formação, muitos docentes da área de Ciências Biológicas têm dificuldades em ensinar sobre sexualidade e muitos não se sentem a vontade para debater sobre estas questões com seus discentes em virtude dos seus valores socioculturais, sobretudo os de cunho religioso.

Diante da relevância das temáticas gênero e sexualidade na formação docente, incluindo a dos professores de Ciências e Biologia, este trabalho apresenta e analisa as compreensões sobre gênero e sexualidade em um grupo de educadores participantes de um curso de Licenciatura em Ciências Biológicas para professores já atuantes na educação básica, mas não licenciados nesta área.

\section{Desenvolvimento}

Este estudo está ancorado na abordagem qualitativa (Denzin \& Lincoln, 2006), pois analisou uma situação específica de formação em serviço com suas especificidades, buscou uma interação entre pesquisador e participantes da pesquisa e se preocupou com a compreensão dos pensamentos e opiniões dos licenciandos de um curso específico.

O campo de estudo foi um curso de Licenciatura em Ciências Biológicas vinculado ao Plano Nacional de Formação de Professores da Educação Básica (PARFOR) da Coordenação de Aperfeiçoamento de Pessoal de Nivel Superior (CAPES) e desenvolvido na Universidade Estadual do Sudoeste da Bahia, campus 
Revista Tecné, Episteme y Didaxis: TED. Año 2014, Número Extraordinario. ISSN Impreso: 0121-3814, ISSN web: 2323-0126 Memorias, Sexto Congreso Internacional sobre Formación de Profesores de Ciencias. 08 al 10 de octubre de 2014, Bogotá

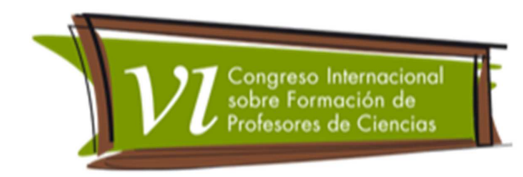

de Jequié. O referido curso é destinado para professores da educação básica que ensinam Ciências e/ou Biologia em escolas estaduais e municipais, mas não habilitados na área.

A carga horária total do curso é de 3035 horas e, dentre os seus componentes curriculares, apresenta os chamados Seminários Temáticos. As discussões sobre gênero e sexualidade foram trabalhadas em três destes seminários, totalizando 45 horas. Os temas abordados nos seminários foram: conceito de gênero, construções de masculinidades e feminilidades na sociedade, violência de gênero, diversidade de gênero e sexual, sexismo e homofobia nas escolas, práticas sexuais, vulnerabilidades e abordagem da sexualidade nas escolas. Já as atividades desenvolvidas foram: exibição e discussão de documentários e filmes, debates, leitura e discussão de artigos científicos, dinâmicas e análise de um conto. Participaram do trabalho, os trinta e sete professores-cursistas frequentes no curso.

Para a discussão desta experiência foram utilizados os escritos dos participantes nas diferentes atividades desenvolvidas ao longo dos componentes curriculares e dos registros do formador e também autor deste trabalho no diálogo com a turma no decorrer dos Seminários Temáticos.

Em relação às discussões de gênero, percebeu-se que, em geral, os professorescursistas apresentaram compreensões binárias. Quando caracterizavam a mulher como vaidosa, o homem era desleixado e se a mulher fosse fiel, o homem era infiel. Estas ideias de gênero demarcam posições fixas e dicotômicas para homens e mulheres, inclusive quando se apresenta características que vão de encontro às compreensões socioculturais esperadas para os gêneros, passa-se a duvidar se a pessoa é "de fato" homem ou se é "realmente" mulher (Louro, 2008).

As características predominantes nas mulheres segundo os cursistas foram: sensibilidade, vaidade e maternidade, já para os homens enfatizaram o autoritarismo, orgulho, força e impulsividade. A característica guerreira apareceu como forma de caracterizar a mulher por acreditarem que ela luta pelos seus anseios, sonhos e projetos, mesmo não tendo, algumas vezes, o apoio social. Neste caso, lutar não está relacionado à força física como, geralmente, se associa ao homem, contudo perturba o ideário de que a mulher é sempre frágil.

Destaca-se também uma comparação que alguns professores-cursistas fizeram ao definir o homem como a cabeça e a mulher como a coluna. Embora 
Revista Tecné, Episteme y Didaxis: TED. Año 2014, Número Extraordinario. ISSN Impreso: 0121-3814, ISSN web: 2323-0126 Memorias, Sexto Congreso Internacional sobre Formación de Profesores de Ciencias. 08 al 10 de octubre de 2014, Bogotá

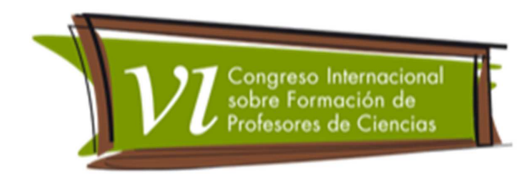

ressaltassem que nesta analogia a mulher era entendida como sustentação, o homem era associado como o pensante, o direcionador das ideias e ações ou como nos dizeres de uma dupla de licenciandas, a "cabeça do lar".

A compreensão do homem como provedor da casa foi citada por alguns licenciandos. Outra característica associada ao homem foi "ter pegada", ou seja, ter iniciativa para chegar até a mulher, cortejando-a e, assim, evidenciando sua virilidade. De certa forma, estes últimos apontamentos reiteram um modelo de masculinidade hegemônica, não favorecendo a ruptura dos padrões de gênero, mas colaborando na sustentação de sua assimetria. Como ressaltado por Connell \& Messerschmidt (2013, pág. 260): "Para se sustentar um dado padrão de hegemonia é necessário o policiamento de todos os homens, assim como a exclusão ou o descrédito das mulheres".

Nas reflexões sobre diversidade sexual por meio da discussão do filme "Pra que time ele joga" e de situações do cotidiano dos cursistas, perguntou-se como reagiriam caso soubessem que seu/sua filho/filha fosse homossexual. Daqueles que estavam presentes no dia, a maior parte mencionou que buscaria a aceitação, embora ressaltassem as dificuldades, além do fato de alguns alegarem não esperar gays ou lésbicas em suas famílias. Os principais argumentos para o apoio à/ao filha/filho foram: o amor pelo/pela filho/filha; impedir o distanciamento; desejar a felicidade dela/dela; ajudar na superação dos preconceitos e evitar problemas maiores no futuro. Um grupo menor não aceitaria e procuraria corrigir por meio do diálogo buscando convencê-lo(a) de que está no "caminho errado", levando-o(a) para a Igreja ou a(o) encaminhando a um "tratamento psicológico", pois a homossexualidade é vista para estes como algo não divino, pecado ou desvio psíquico.

Embora alguns dos cursistas desejassem "corrigir" a homossexualidade, a maioria compreendeu as múltiplas formas de orientação sexual como expressão da sexualidade, evidenciando avanços na visão destes professores, pois pesquisas como a de Ribeiro (2007) e Souza \& Diniz (2010) destacam que boa parte do corpo docente apresenta um discurso discriminatório velado, pois aceitam o gay ou a lésbica em suas aulas para não serem vistos como preconceituosos, outras vezes querem culpabilizá-los pela exclusão a que são submetidos.

Outra questão abordada com a turma foi sobre os relacionamentos afetivossexuais. Os debates foram feitos com base em situações vivenciadas na atualidade confrontando com as relações ocorridas na época em que os 
Revista Tecné, Episteme y Didaxis: TED. Año 2014, Número Extraordinario. ISSN Impreso: 0121-3814, ISSN web: 2323-0126 Memorias, Sexto Congreso Internacional sobre Formación de Profesores de Ciencias. 08 al 10 de octubre de 2014, Bogotá

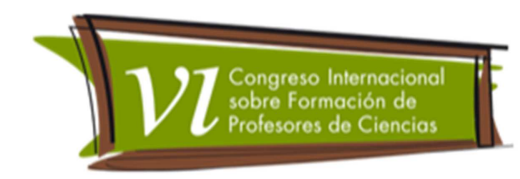

professores-cursistas eram adolescentes e jovens. Mencionaram que em épocas anteriores havia muita proibição e vigilância sobre as relações amorosas, sobretudo com as mulheres e muitas delas não tinham liberdade de escolha dos seus parceiros, tendo que, por exemplo, namorar escondido dos familiares e não terminar os relacionamentos quando desejavam, pois eram "mal vistas". Mencionaram também sobre a ampliação das informações sobre o sexo e os métodos contraceptivos, algo pouco presente em épocas passadas. Como menciona Justo (2005, pág. 75): "O amor confluente é expressão dos avanços das conquistas de maior igualdade nas relações de gênero, da liberdade quanto às escolhas de parceiros e interrupções de relacionamentos conjugais (...)".

Também ressaltaram o valor da virgindade em momentos anteriores e o quanto isto aprisionava as mulheres, inclusive uma das cursistas relatou a história de uma garota que já não era mais virgem e para se casar, a mãe banhava a vagina com aroeira todos os dias para que o noivo não desconfiasse quando ela se casasse. Segundo ela havia o seguinte ditado: "Aroeira é um pau santo que Deus abençoou, buraco que ninguém fecha, aroeira veio e fechou". Por outro lado, muitos professores-cursistas questionaram as incertezas e instabilidades de muitos relacionamentos da contemporaneidade (como liberdade excessiva e desvalorização do corpo) gerando ideias conflituosas sobre o tema.

Ao se trabalhar com vulnerabilidades e prevenção não com o intuito de gerar medo, mas de trazer a rede de fatores que interferem neste processo, utilizou-se de uma reportagem sobre a aids veiculada nos meios de comunicação em 27 de março de 1983 para que os professores-cursistas compreendessem a dinâmica da ciência, sua vinculação com o contexto histórico, social, cultural e político e como no início da epidemia da aids houve muitas especulações que geraram preconceitos e discriminações contra homossexuais, hemofilicos e usuários de drogas injetáveis.

Quando se trabalhou com algumas ideias dos participantes sobre a prevenção e a vulnerabilidades ligadas ao contágio da aids, observou-se, por exemplo, que boa parte estava desatualizada em relação à algumas informações importantes como o desconhecimento sobre os riscos da transmissão da aids de uma possivel mãe soropositiva para o filho durante a gestação, parto ou amamentação e também da existência da janela imunológica (intervalo de tempo entre o contágio e a produção de anticorpos no sangue). Ao se dialogar sobre o preconceito em relação ao soropositivo, notou-se que mais da metade dos licenciandos ainda utilizavam do termo "aidético" para se referir às pessoas que 
Revista Tecné, Episteme y Didaxis: TED. Año 2014, Número Extraordinario. ISSN Impreso: 0121-3814, ISSN web: 2323-0126

Memorias, Sexto Congreso Internacional sobre Formación de Profesores de Ciencias. 08 al 10 de octubre de 2014, Bogotá

convivem com o vírus HIV e alguns isolariam alguém que fosse soropositivo, pois teriam receio de contrair o vírus, mesmo tendo ciência de que a transmissão não se dá por meio do abraço, beijo, aperto de mão, ou partilhando talheres, copos, banheiro e entre outros. Ideias estereotipadas e discriminatórias sobre as pessoas soropositivas também foram identificadas em pesquisa feita por Seidl, Ribeiro \& Galinkin (2010) com estudantes universitários, sendo que uma parcela deles não concordaria que uma criança soropositiva frequentasse a escola, seria favorável a demissão de uma pessoa que tivesse o vírus HIV e não apoiaria que uma mulher soropositiva tivesse filhos.

Durante o desenvolvimento do trabalho houve alguns empecilhos e embates, dentre eles destacam-se: a rejeição de poucos licenciandos em participarem das atividades como exibição de filme ou mesmo a produção escrita por conta do seu posicionamento religioso e o questionamento de alguns no que se refere à relevância do tema para sua formação.

\section{Conclusōes}

Em síntese, as discussões sobre gênero e sexualidade na formação de um grupo de professores não licenciados em Ciências Biológicas evidenciaram as dificuldades em romper com as normas e os enquadramentos de gênero e de sexualidade, porém, notou-se que a maioria dos cursistas passou a reconhecer as diferenças e se sentiu mais preparada para debater essas questões na escola embora reconheçam, em alguns casos, obstáculos como o questionamento dos familiares, o medo de terem a "imagem comprometida" e os discursos religiosos fundamentalistas.

\section{Referências Bibliográficas}

César, M.R.A. (2009). Gênero, sexualidade e educação: notas para uma "epistemologia". Educar em Revista, (35), pág. 37-51.

Connell, R.W. \& Messerschmidt, J.W. (2013). Masculinidade hegemônica: repensando o conceito. Revista Estudos Feministas, 21 (1), pág. 241-282.

Denzin, N.K. \& Lincoln, Y.S. (2006). O planejamento da pesquisa qualitativa: teorias e abordagens. (2 ed). Porto Alegre: Artmed.

Figueiró, M.N.D. (2010). Educação sexual: retomando uma proposta, um desafio. (3 ed). Londrina: Eduel. 
Revista Tecné, Episteme y Didaxis: TED. Año 2014, Número

Extraordinario. ISSN Impreso: 0121-3814, ISSN web: 2323-0126

Memorias, Sexto Congreso Internacional sobre Formación de Profesores de Ciencias. 08 al 10 de octubre de 2014, Bogotá

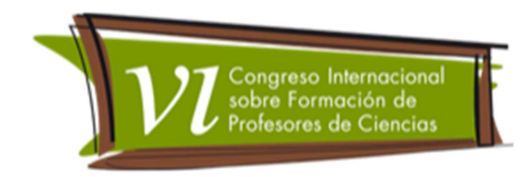

Justo, J.S. (2005). O "ficar" na adolescência e paradigmas de relacionamento amoroso da contemporaneidade. Revista do Departamento de Psicologia, 17(1), pág. 61-77.

Louro, G.L. (2008). Gênero e sexualidade: pedagogias contemporâneas. ProPosições, 19 (2), pág. 17-23.

Ribeiro, C.R.S. (2007). Uma certa banda de música: representações sobre a homossexualidade em uma escola pública. Educação \& Realidade, 32 (2), pág. 23-48.

Seidl, E.M.F., Ribeiro, T. R. A. \& Galinkin, A. L. (2010). Opiniões de jovens universitários sobre pessoas com HIV/AIDS: um estudo exploratório sobre preconceito. Psico-USF, 15 (1), pág. 103-112.

Silva, R.C.P. \& Megid Neto, J. (2006). Formação de professores e educadores para abordagem de educação sexual na escola: o que mostram as pesquisas. Revista Clência e Educação, 12 (2), pág. 185-197.

Souza, C.L, Dinis, N.F. (2010). Discursos sobre homossexualidade e gênero na formação docente em biologia. Pro-Posições, 21 (3), pág. 119-134. 